\title{
New Approaches, New Mechanisms Needed
}

The OECD Megascience Forum, having made recommendations for astronomy and Earth drilling, now looks further afield. Françoise Praderie, the Programme Coordinator, reports.

The Megascience Forum of the Organization for Economic Co-operation and Development $(\mathrm{OECD})$ considers at its next meeting in July 1993 the area of global change research, and an expert meeting will be held at the end of this month (March 1993) in Cambridge, Massachusetts (USA). Areas to be reviewed later in 1993 include oceanography and, possibly neutron sources and synchrotron radiation. The Forum will also be discussing generic science and technology policy issues related to the development and management of megascience, such as national decision-making processes.

The Forum has its roots in a new concern of governments of the industrialised countries to enhance international cooperation in megascience. This encompasses classical fields such as high-energy physics, astronomy, and space physics where progress is often made only by using large and even very large facilities, allowing one to perform experiments at the frontiers of a discipline to obtain novel, otherwise unattainable, results. Megascience is now seen to include largescale programmes which have taken shape the last 10 years in areas such as the study of the Earth and global change research.

Since big-science projects, often called megaprojects, and large-scale distributed programmes tend to be more and more expensive, governments have initiated policy discussions to encourage a reasonable development of megascience without jeopardising small science. Research ministers from the 24 Member countries of OECD, meeting in March 1992 in Paris, agreed that "there is an urgent need for a process for the exchange of information and for open substantive discussion between the governments of Member countries at an earlier formative stage on the planning, development and financing of big-science projects and largescale programmes. This would help promote a coherent approach on a world scale to projects and programmes with significant financial and manpower implications, hence optimising scarce resources."

The Megascience Forum they recommended was created in June 1992 by the OECD Council. Composed of senior government officials, it meets twice a year and is hosted by the OECD. Dr. P.A.J. Tindemans, Director General for Research and Science Policy in The Netherlands' Ministry of Educa. tion and Science, was elected Chairman at the 1st Meeting, on 6 July 1992, and re-elected at the 2nd Meeting on 12-13 January 1993.

At its 1st Meeting, the Forum agreed to start with a review of astronomy and Earth drilling (both deep sea and deep continental) so as to assess existing mechanisms for international co-operation and to identify the most important future facilities proposed or under discussion. Two expert meetings were then held, one at the Institute of Astrophysics of the Canary Islands and the second at the Research Centre of IFREMER in Brest. Preliminary versions of the reports prepared after the meetings were submitted to the
Forum's 2nd Meeting (the reports will be published in their finalised forms*). The expert meetings proved to be valuable mechanisms for achieving the objectives, and the reports help develop dialogue, at the international level, between the scientific community and government.

\section{Astronomy is Both Big and Little Science}

The astronomy report includes a general view of scientific objectives, an overview of current research, an inventory of present large facilities, an analysis of co-operation mechanisms, and a discussion of new projects and future concepts for megaprojects. Mechanisms have existed for several decades to examine, at the scientific level, future projects, to create international support for projects to be put forward to governments for funding, and to undertake cooperation. New coordinating mechanisms appeared unnecessary since international cooperation seemed likely to continue to develop. However, a change of approach will be essential for some future concepts (e.g., the International Antarctic Observatory, the Lunar Observatory) as they can only be realised at the global level, owing not only to the costs involved, but also because of political considerations related to sites which are international in nature.

The most crucial issues stem from the need to ensure continuity in planning, building and exploiting megaprojects in astronomy. Requirements include: incorporating operation costs in the announced cost; efficient collection, standardization, processing, and use of data, notably (although not exclusively) from ground-based instruments; and long-term manpower management.

Russia, an observer to the Forum, indicated that it aims to participate in multilateral collaborations for ground-based astronomy (its space astronomy programme has been open to co-operation for two decades). It hopes that the Forum will present a consolidated view of the status of future projects and concepts proposed or envisaged, so as to facilitate the decision-making process for prospective partners.

\section{New Collaborations Urged for Drilling}

With regard to Earth drilling, the expert meeting indicated that the scientific community was beginning to link the potential results of deep drilling with many scientific, social and economic problems of great and sometimes urgent international concern. It concluded that much greater international $\mathrm{co}$ operation is called for in continental drilling. Although there is already good cooperation in ocean drilling, more visionary planning is needed in view of the large number of new options for the next phase of activities.

The Forum therefore encourages the countries - in particular, Germany, Russia, Japan, the USA, the UK, and France - that have been willing to take an active part in furthering global cooperation to continue their efforts. Second, the geosciences community

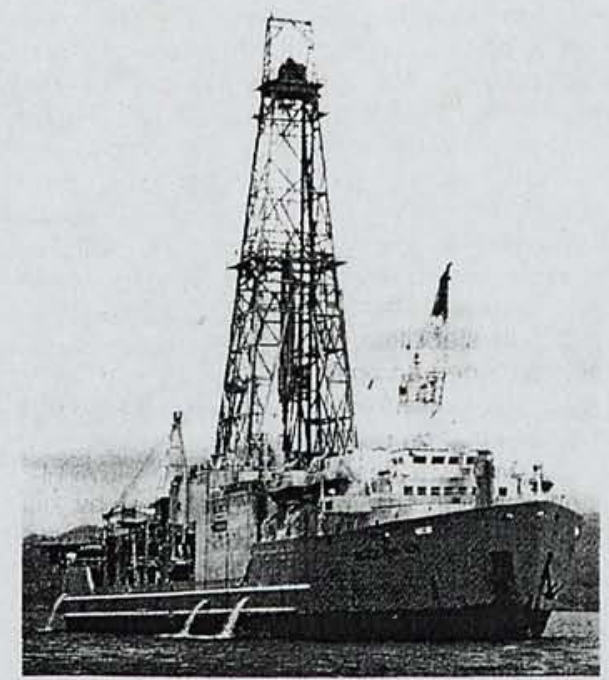

The research vessel "JOIDES Resolution" employed in Germany's ocean floor drilling programme.

is encouraged to work towards a international strategy for deep drilling that includes lon: range scientific plans, the formation of common databases, and an assessment of exist ing and new facilities. Germany is commended for accepting the scientific lead rôle in the area of continental scientific drilling, and the Forum looks forward to the planned Potsdam Conference in August 1993 as it represents an important step in developing new institutional forms of cooperation to provide better coordination between participating governments.

The Forum supports the use of the existing Ocean Drilling Programme (ODP) scientific advisory structure as a mechanism for making new long-range plans for exploiting proposed new drilling facilities such as the Japanese Deep Drilling Ship, the French NEREIS programme, and the Russian drill ship reinforced for Arctic drilling. But it will be important to ensure clear and direct links between the particular objectives and the scientific objectives of the deep drilling community as a whole.

- Further information about the OECD Mega science Forum's reports on astronomy and on Earth drilling is available from Dr. F. Praderie, Programme Coordinator, OECD, Directorate for Science, Technology and Industry, Science \& Technology Policy Division, 2, rue Andre Pascal, F-75775 Paris Cédex 16. (Tel.: +33-1. 452492 89; fax: +33-1-45 249767 ).

\section{Europhysics Industrial Workshops}

Europhysics Industrial Workshops aim to promote an interchange between experts from industry, academia and centres on advanced topics. The following have been announced so far for 1993/4:

- EIW-10: Acoustical Imaging (Oxford, UK: 25-28 August 1993)

- EIW-9: Nanometre-Scale Methods in XRay Technology (Veldhoven, The Netherlands; $11-13$ Oct. 1993)

- EIW-11: Thermal Microsensors - Their Basis, Principles and Applications Jena, Germany; Spring 1994).

Refer to the meetings listing (pp. 31-42) for details, or ask the EPS Secretariat. 